\title{
Association distribution characteristics of natural and artificial Larix gmelinii forests along environmental gradients in northeast China
}

\section{Xiaohang Bai ( $\sim$ baixh@iae.ac.cn )}

Institute of Applied Ecology Chinese Academy of Sciences https://orcid.org/0000-0002-6949-2299

Jinghua Yu

Institute of Applied Ecology Chinese Academy of Sciences

Shusheng Yuan

Institute of Applied Ecology Chinese Academy of Sciences

Yihong Tan

Institute of Applied Ecology Chinese Academy of Sciences

Research article

Keywords: Species diversity, Plant association, Two-way indicator species analysis, Canonical correspondence analysis, Environmental gradient

Posted Date: July 30th, 2019

DOI: https://doi.org/10.21203/rs.2.12122/v1

License: (9) This work is licensed under a Creative Commons Attribution 4.0 International License.

Read Full License 


\section{Abstract}

Background: Larix gmelinii forest is one of coniferous forests in cold-temperate zone, which is a vital part of national strategic landscape of ecological security of China. Plant association distribution is different in natural and artificial Larix gmelinii forests, meanwhile, determining mechanisms in typical associations of Larix gmelinii forests still need to be explored. The study focused on which environmental factors actuated association distribution of natural and artificial Larix gmelinii forests in northeast China. Two-way indicator species analysis (TWINSPAN) and canonical correspondence analysis (CCA) were used to classify plant associations and explored the relationship between species and environment. Results: All the plots $(n=175$, size $=30 \mathrm{~m} \times 30 \mathrm{~m})$ of Larix gmelinii forests were classified into 6 plant associations by TWINSPAN. Species diversity in natural forests were higher than that in artificial forests. Ass.III and Ass.IV only appeared in natural forests, meanwhile, Ass.VI only appeared in artificial forests. The primary environmental drivers of species diversity patterns in natural forests were annual mean temperature, followed by annual precipitation, elevation, slope aspect, and canopy density. However, elevation and annual precipitation had strong effects in determining association distribution in artificial forests. Conclusions: Plant association distribution showed habitat preferences, besides, natural forests had higher species diversity and more resistance than artificial forests. The study can be used as a reference for Larix gmelinii forest ecosystem protection in northeast China and a theoretical basis for scientific management in similar areas.

\section{Background}

Exploring plant community assembly has long been a central issue for understanding species coexistence and biodiversity maintenance in community ecology [1]. At biogeographical scales, patterns of spatial species turnover provided important insights into historical and regional processes underlying the composition and dynamics of regional biotas [2]. At local scales, spatial community dissimilarity was driven by several non-mutually exclusive processes, including dispersal limitation, habitat filtering and species interactions [3]. Dispersal, biotic interactions, and gap dynamics were likely to produce spatial structure most evident at relatively fine scales depending on underlying geomorphology [4]. Environmental heterogeneity was inherently spatially auto-correlated, and thus the use of spatially variables helped to account for its variation, and also the spatial scale at which they influenced $\beta$ diversity [5]. Comparisons among ecological or taxonomic groups are necessary to gain a more comprehensive understanding of diversity patterns [6].

Larix gmelinii forests with a deciduous needle leaf conifer are adapted to grow in harsh climates and widely distribute over a range from $40^{\circ} \mathrm{N}$ to $72^{\circ} \mathrm{N}$ and $110^{\circ} \mathrm{E}$ to $130^{\circ} \mathrm{E}$ [7]. They are dominant timber tree species in northern China. To meet the needs of the timber production, most of the larch plantations are developed by replacing the secondary forests. The total area of larch plantations reaches $2.61 \times 106$ ha [8]. However, the soil fertility of larch plantations declined gradually due to single species composition and mono ecosystem structure [9]. Understanding community composition difference is the foundation for sustainable development of Larix gmelinii forests with the main purpose of timber production and 
ecological function [10]. In tropical forests, it was found that nearly four-fifth of the species examined were associated with topographically defined habitats [11]. Recent research focused on quantitative analysis to quantify the relative importance of environmental drivers on community composition and structure [12]. How environmental variation limits plant association distribution is of considerable current interest.

In the study, climate, topography and canopy density were considered as environmental variables. TWINSPAN and CCA were used to analyze the relationship between species distribution and environmental variables. The study was designed to answer the following questions: (1) What is the present situation in terms of species composition and structure for natural and artificial Larix gmelinii forests? (2) Which environmental factors affected different association distribution patterns in natural and artificial Larix gmelinii forests? Based on the questions, we expected to find out the limiting environmental factors and provide important guidance for managing and protecting Larix gmelinii forests.

\section{Materials And Methods}

\section{Study area}

The study was conducted from July to September each year from 2016 to 2018. Based on typical and comprehensive sampling methods, a total of 175 Larix gmelinii forest plots (130 natural Larix gmelinii forest plots and 45 artificial Larix gmelinii forest plots) were investigated in the Khingan Mountains $\left(118.83^{\circ} \mathrm{E}-135.09^{\circ} \mathrm{E}, 38.72^{\circ} \mathrm{N}-53.56^{\circ} \mathrm{N}\right)$ (Fig.1). The region belongs to a cold temperate continental monsoon climate zone with a mean annual temperature and precipitation of $-4^{\circ} \mathrm{C}-11.5^{\circ} \mathrm{C}$ and $400-1100$ $\mathrm{mm}$, respectively. The elevation ranges from 200 to $1400 \mathrm{~m}$ a.s.l. The annual sunshine duration is $2300-$ $3000 \mathrm{~h}$ and frost-free period is 100-160 d. The zonal vegetation types in the area are forest, shrub, grassland, wetland meadow, marsh, and aquatic vegetation. The most common tree species are Larix gmelinii, Pinus pumila, Betula platyphylla, Populus davidiana. Pinus pumila shrubs, Larix gmelinii forest and wetland distribute vertically from high to low along altitude. The soil type is brown coniferous forest soil, meadow soil, boggy soil [13].

\section{Data collection}

The plots basically covered the distribution range of Larix gmelinii forests in northeast China. The size of forest plots was $900 \mathrm{~m}^{2}$ (30 m×30 m), and consisted of nine $10 \mathrm{~m} \times 10 \mathrm{~m}$ subplots [14]. Plant species in tree, shrub, and herbaceous layers were recorded in each plot. Species name, diameter at breast height $(\mathrm{DBH})$, and height of all individual trees with a $\mathrm{DBH} \otimes 2.5 \mathrm{~cm}$ were investigated. Two of the nine subplots were selected for a survey of the shrub layer at the cross corners. Species name, abundance, and average height of all woody individuals with $\mathrm{DBH} \otimes 2.5 \mathrm{~cm}$ (including sapling trees) were recorded. Five $1 \mathrm{~m} \times 1 \mathrm{~m}$ herbaceous quadrats within each subplot were set up. Species name, average coverage, and average height of each vascular species occurring in the herbaceous quadrats were recorded. 
Climate data that contained with 19 bioclimatic variables with $30 \mathrm{~s}(\mathrm{ca} .1 \mathrm{~km})$ spatial resolution obtained was from the World Climate Database (www.worldclim.org). Detrended canonical correspondence analysis suggested that mean annual temperature (bio1) and annual precipitation (bio12) as climatic variables were more appropriate than others. Habitat factors were recorded, including altitude, slope, aspect, canopy density and disturbance. Ultimately, 6 environmental factors that mainly influenced species distribution of Larix gmelinii forests were added to model operation.

\section{Data analysis}

Species importance value (IV) was used as the basic data in multivariate analysis. The species data matrix functions were consisted of importance values of 399 species in 130 natural Larix gmelinii forests plots $(399 \times 130)$ and 309 species in 45 artificial Larix gmelinii forests plots $(309 \times 45)$. TWINSPAN is one of common methods in vegetation classification [15]. We named associations after the dominant species in the tree layer, followed by indicators species of shrub layers. CCA ordination can represent the variation of a data matrix in a reduced number of dimensions [16]. The TWINSPAN classification, CCA ordination and species diversity were calculated by R software. (see Calculations in Supplemental Files)

\section{Results}

\section{Association classification in natural and artificial Larix gmelinii forests}

There were totally 423 species in all the plots, belonging to 212 genera, 79 families. The species belonging to Compositae and Ranunculaceae of the angiosperms held a dominant position in the species community composition. Natural forests were classified into 5 plant associations by TWINSPAN, including Ass.I (Larix gmelinii-Betula fruticosa-Carex meyeriana), Ass.II (Larix gmelinii-Spiraea chamaedryfolia+Corylus heterophylla-Eriophorum vaginatum), Ass. III (Larix gmelinii-Ledum palustre+Vaccinium vitis-idaea-Deyeuxia angustifolia), Ass.IV (Larix gmelinii-Rhododendron dauricumPyrola dahurica), Ass.V (Larix gmelinii-Carex) (Table 1). Artificial forests were classified into 4 plant associations by TWINSPAN, including Ass.I (Larix gmelinii-Betula fruticosa-Carex meyeriana), Ass.II (Larix gmelinii-Spiraea chamaedryfolia+Corylus heterophylla-Eriophorum vaginatum), Ass.V (Larix gmeliniiCarex), Ass.VI (Larix gmelinii-Carex Larix gmelinii-Sorbaria sorbifolia-Geranium wilfordii) (Table 2).

\section{The response of different associations to environmental gradients}

In the CCA analysis, the Monte Carlo permutation test indicated significant eigenvalues for all canonical axes $(P \otimes 0.01)$. The species-environment correlations of CCA axes respectively were $0.944,0.777,0.806$, 0.708 . The cumulative percentage variance of the species-environment relationship for CCA axes was $83.5 \%$ in natural forests (Table 3 ). The species-environment correlations of CCA axes respectively were $0.950,0.922,0.862,0.861$. The cumulative percentage variance of the species-environment relationship for four CCA axes was $80.4 \%$ in artificial forests (Table 4). CCA ordination performed well in plant association distribution along environmental gradients. In addition, natural forests had better fitting effect than artificial forests. 
In two-dimensional CCA ordination diagram of natural forests, Asso.I and Asso.III usually distributed in higher elevation and slope, shady slope, lower annual mean temperature. Asso.Il was immensely limited by annual precipitation, and mainly distributed in moist sunny slope with higher canopy density. Asso.IV usually distributed in cold shady slope with lower annual precipitation. Asso.V usually distributed in lower elevation and more flat areas (Fig.2). In artificial forests, Asso.I distribution trends was similar to the trends in natural forests. Asso.Il and Asso.V were usually distributed in lower elevation with higher canopy density. Asso.VI was immensely limited by annual mean temperature and annual precipitation in lower elevation (Fig.3).

\section{The main limiting environmental factors and species diversity patterns in different associations}

In natural forests, environmental variable ranking of marginal effects in order was annual mean temperature, annual precipitation, elevation, slope aspect, canopy density, slope. Five environmental factors had significant marginal effects on community distribution $(P<0.05)$. Removing the collinearity of leading factors, only 5 environmental factors past through significance test. The conditional effect order of environmental factors didn't change (Table 5).

In artificial forests, environmental variables ranking of marginal effects in order was elevation, annual mean temperature, annual precipitation, slope aspect, canopy density, slope. Five environmental factors had significant marginal effects on community distribution $(P<0.05)$. Removing the collinearity of leading factors, only 2 environmental factors past through significance test. The conditional effect order of environmental factors changed, and ranking of environmental variables in order was elevation and annual precipitation (Table 6).

Species richness ranged from 16.07 to 28.18 , the Shannon-Wiener index ranged from 1.98 to 2.44 , and evenness ranged from 0.69 to 0.81 in natural forests (Fig.4). Species richness ranged from 14.25 to 26.18, the Shannon-Wiener index ranged from 1.56 to and 2.46 evenness ranged from 0.58 to 0.71 in artificial forests (Fig.5). Ass.III and Ass.IV only appeared in natural forests and Ass.VI only appeared in artificial forests. Species diversity in Ass.I, Ass.II, Ass.V of natural forests were higher than that of artificial forests.

\section{Discussion}

Larix gmelinii forests are major components of temperature coniferous forests in northern China, and play an important role in climate change mitigation, water and soil conservation, and resource conservation [17]. Based on a field investigation of Larix gmelinii forests, we found that the composition of plant flora was rich, but significantly different among different mountain areas due to the complex topographic conditions and high spatial heterogeneity. In all plots, Compositae and Ranunculaceae of the angiosperms held a dominant position in the species community composition. The classification demonstrated that Ass.III and Ass. IV only appeared in natural forests and Ass. VI only appeared in artificial forests. The results were in accordance with facts that Ledum palustre, Vaccinium vitis-idaea and Rhododendron dauricum usually appeared in stable community of Larix gmelinii forests [18]. However, 
Sorbaria sorbifolia and Geranium wilfordii were partial to distribute in lower altitude e and often appeared in artificial forests with strong disturbance [19]. Compared with the natural forests, some shrub layer was absent in the artificial forests. A tendency of increasing clustering for the woody plants along the temperature gradient, and indicated that environmental filtering drove the closely related species to occur in the same community [20]. The results of our study were consistent with other studies, which indicated environmental filtering might drive the community structure at a broad scale [21]. The Monte Carlo permutation test showed significant species-environment correlations with the CCA axes and natural Larix gmelinii forests showed better imitative effect.

Species diversity is an important feature of forest composition and structure, and its change is frequently used as an indicator of forest dynamics. Many researchers had pointed out that species richness was often strongly correlated with climate. However, most of the previous studies at a large scale were based on species richness within geographic grids [22]. In the analysis, the data at plot scale was used to examine geographic diversity patterns in relation to climate. It was found that species diversity in natural forests were higher than that in artificial forests due to natural environment and association type. Higher canopy cover might cause a decrease in the redundancy of species with similar characteristics. The limited light conditions, microhabitat and interspecific competition played important roles in the patterns of species diversity for the artificial forests [23]. Stands at early successional stages were typically dominated by shade intolerant, nutrient demanding, and fast growing species, which resulted in phylogenetic and functional clustering, due to the availability of abundant resources subsequent to a disturbance [24]. Late-successional communities were more often dominated by shade tolerant, slowed growing and distantly related species with dissimilar functional traits, which were characterized by phylogenetic and functional over dispersion caused by competitive exclusion as resources become limited [25]. Such transformation has been generally attributed to shifts in community assembly processes, from environmental filtering to competitive exclusion [26]. Species diversity in the natural forests was more stable, however, higher coverage might limit light availability and enhance interspecific competition. Therefore, plant community would like to regulate themselves to maintain appropriate biodiversity as succession.

Marginal effect and conditional effect provided ranking of environmental variables in order of importance in Larix gmelinii forests. The differences in forest type and structure caused the variations in light condition, soil property, interference intensity, which had strong effects in determining species composition and interspecific relationships [27]. CCA performed well in describing association distribution along environmental gradients. Due to the complex topographical conditions and high spatial heterogeneity in natural forests, the primary environmental drivers of species diversity patterns were mean annual temperature, followed by annual precipitation, elevation. Most studies have shown that the patterns and underlying mechanisms of woody plants and herbaceous plants were different due to the different response patterns [28]. As to natural forests, more environmental factors took part in determining species distribution, such as annual mean temperature, annual precipitation, elevation, slope aspect, canopy density. The results suggested that natural forests were relatively well developed and the system stability was affected by climatic, topographic, structural factors [29-32]. Nutrient resorption of 
plants can respond to the variation of soil nutrients by reducing the dependence of plants on soil nutrient supply to ensure their maximum growth [33]. Elevation and annual precipitation had strong effects in determining association distribution of artificial forests. Overall, habitat preferences of association distribution in Larix gmelinii forests were obvious, besides, natural forests had higher species diversity and more resistance than artificial forests.

\section{Conclusions}

Plant association distribution showed habitat preferences in natural and artificial Larix gmelinii forests. Objective guidelines was established to reflect actually association spatial situation of Larix gmelinii forests by CCA. Natural forests were more resistant to disturbance than artificial forests. The results demonstrated that association distribution was affected by multiple environmental and ecological variables acting at different spatial scales overtime. The primary environmental drivers of species distribution in natural forests were annual mean temperature, followed by annual precipitation, elevation, slope aspect, canopy density. In addition, elevation and annual precipitation had strong effects in determining association distribution in artificial forests. Our results provided a theoretical basis for scientific conservation and restoration of Larix gmelinii forests in northeast China.

\section{Abbreviations}

TWINSPAN: two-way indicator species analysis; CCA:canonical correspondence analysis; Ass.I: Larix gmelinii-Betula fruticosa-Carex meyeriana; Ass.II: Larix gmelinii-Spiraea chamaedryfolia+Corylus heterophylla-Eriophorum vaginatum; Ass. III: Larix gmelinii-Ledum palustre+Vaccinium vitis-idaeaDeyeuxia angustifolia; Ass.IV: Larix gmelinii-Rhododendron dauricum-Pyrola dahurica; Ass.V: Larix gmelinii-Carex; Ass.VI: Larix gmelinii-Carex Larix gmelinii-Sorbaria sorbifolia-Geranium wilfordii.

\section{Declarations}

\section{Authors' contributions}

XHB conceived and designed the experiments; XHB, JHY,SSY and YHT conducted the fieldwork and collected the data; $\mathrm{XHB}$ analyzed the data, interpreted the results, provided the manuscript and reviewed the article. All authors read and approved the final manuscript.

\section{Author details}

CAS Key Laboratory of Forest Ecology and Management, Institute of Applied Ecology, Chinese Academy of Sciences, Shenyang 110016, China. 
Acknowledgments

Our gratitude to two anonymous reviewers for their comments and helpful suggestions to improve an earlier version of the manuscript. Their contributions were fundamental for the success of our study.

\section{Competing Interest}

The authors declare that they have no competing interests.

\section{Consent for publication}

Not applicable.

\section{Ethics approval and consent to participate}

Not applicable.

\section{Funding}

This study was supported by Natural Science Foundation of Liaoning Province (Grant No.20180540005) and the 13th Five-year Informatization Plan of Chinese Academy of Sciences (Grant No. XXH13506).

\section{Publisher's Note}

Springer Nature remains neutral with regard to jurisdictional claims in published maps and institutional affiliations.

\section{References}

1. Wang XG, Wiegand T, Anderson-Teixeira KJ, Bourg NA, Hao ZQ, Howe R, Jin GZ, Orwig DA, Spasojevic MJ, Wang SZ, Wolf A, Myers Ecological drivers of spatial community dissimilarity, species replacement and species nestedness across temperate forests. Global Ecol. Biogeogr. 2018,1-12.

2. Qian H, Ricklefs Disentangling the effects of geographic distance and environmental dissimilarity on global patterns of species turnover. Global Ecol. Biogeogr. 2012, 21, 341-351. 
3. Morlon H, Chuyong G, Condit R, Hubbell S, Kenfack D, Thomas D, Green JL. A general framework for the distance-decay of similarity in ecological communities. Ecol. Lett. 2008,11, 904-917.

4. Jones MM, Tuomisto H, Borcard D, Legendre P, Clark DB, Olivas Explaining variation in tropical plant community composition: influence of environmental and spatial data quality. Oecologia 2008,155,593-604.

5. Legendre P, Mi XC, Ren HB, Ma KP, Yu Partitioning beta diversity in a subtropical broad-leaved forest of China. Ecology 2009,90,663-674.

6. Lan GY, Hu YH, Cao M, Zhu Topography related spatial distribution of dominant tree species in a tropical seasonal rain forest in China. Forest Ecol. Manag. 2011, 262, 1507-1513.

7. Zyryanova OA, Yaborov VT, Tchikhacheva T L, Koike T, Makoto K, Matsuura Y, Zyryanov The structure and biodiversity after fire disturbance in Larix gmelinii (Rupr.). Eurasian J. For. Res. 2007, 10, 19-29.

8. Sun BF, Zhao H, Lu F, Wang XK. Spatial and temporal patterns of carbon sequestration in the northeastern forest regions and its impact factors analysis. Acta Ecol. 2018, 38(14),4975-4983. (In Chinese)

9. Yan T, Zhu JJ, Yang K, Yu Aboveground biomass and nutrient distribution patterns of larch plantation in a montane region of eastern Liaoning Province, China. Chin.J.Appl.Ecol. 2014,25(10):2772-2778. (In Chinese)

10. Hao ZQ, Zhang J, Song B, Ye J, Li Vertical structure and spatial associations of dominant tree species in an old growth temperate forest. Forest Ecol. Manag.2007,252,1-11.

11. Gunatilleke CVS, Gunatilleke IAUN, Esufali S, Harms KE, Ashton PMS, Burslem DFRP, Ashton Specieshabitat associations in a Sri Lankan dipterocap forest. J.Trop.Ecol. 2006,22,371-378.

12. Zhao H, Wang QR, Fan W, Song The relationship between secondary forest and environmental factors in the southern Taihang Mountains. Sci.rep.2017, 7,16431.

13. Jiang YG, Zhang JH, Han SJ, Chen ZJ, Setala H, Yu JH, Zheng XB, Guo YT, Gu Radial growth response of Larix gmelinii to climate along a latitudinal gradient in the Greater Kinggan Mountains, Northeastern China. Forests 2016,7,295.

14. Yuan SS, Tang TT, Wang MC, Chen H, Zhang AH, Yu Regional scale determinants of nutrient content of soil in a cold-temperate Forest. Forests 2018,9,177.

15. Legendre P, Legendre L. Numerical ecology. Oxford: Elsevier Press. 2012.

16. Borcard D, Gillet F, Legendre P. Numerical ecology with R. New York (NY):Springer Press. 2011.

17. Dong LB, Liu ZG, Bettinger Nonlinear mixed-effects branch diameter and length models for natural Dahurian larch (Larix gemelinii) forest in northeast China. Trees 2016,30,1191-1206.

18. Wang ZX, Zhou M, Zhao PW, Wang D, Yang L, Ding Study on species diversity and aboveground biomass of burned phytocoenosium under different burntwood management modes-Taking frigidtemperate zone Larix gmelinii as an Example. Forest Res. Manag. 2018,4,28-33. (In Chinese)

19. Wang Study on characteristics of plant communities at burned area of Daxing'an Mountains. Inner Mongolia Agricultural University. 2016. (In Chinese, master's thesis) 
20. Dong SK, Tang LK, Zhang XF, Liu SL, Liu QR, Su XK, Zhang Y, Wu XY, Zhao ZZ, Li Y, Sha W. Relationship between plant species diversity and functional diversity in alpine grasslands. Acta Ecol.Sin.2017,37(5),1472-1483. (In Chinese)

21. Harrison S, Safford HD, Grace JB, Viers JH, Davies Regional and local species richness in an insular environment: serpentine plants in California. Ecol. Monogr. 2006,76(1),41-56.

22. Swenson The role of evolutionary processes in producing biodiversity patterns, and the interrelationships between taxonomic, functional and phylogenetic biodiversity. Am.J.Bot. 2011,98, 472-480.

23. Wang Effects of thinning on early regeneration processes of broadleaved tree species in pure larch plantation forests. University of Chinese Academy of Sciences. 2016. (In Chinese, master's thesis)

24. Liu B, Chen HYH, Yang J. Understory community assembly following wildfire in boreal forests: shift from stochasticity to competitive exclusion and environmental filtering. Front. Plant Sci. $2018,9,1854$.

25. Letcher SG, Chazdon RL, Andrade AC, Bongers F, van Breugel M, Finegan Phylogenetic community structure during succession: evidence from three Neotropical forest sites. Perspect. Plant Ecol. Evol. Syst. 2012,14, 79-87.

26. Purschke O, Schmid BC, Sykes MT, Poschlod P, Michalski SG, Durka Contrasting changes in taxonomic, phylogenetic and functional diversity during a long-term succession: insights into assembly processes. J. Ecol. 2013,101, 857-866.

27. Feng Spatial patterns of species diversity of seed plants in Chian and their climatic explanation. Biodiver.Sci. 2008,16(5),470-476.

28. Hawkins BA, Devries PJ. Tropical niche conservatism and the species richness gradient of North American butterflies. J. Biogeogr. 2009,36(9),1689-1711.

29. Xu YD, Dong SK, Li S, Shen H. Research progress on ecological filtering mechanisms for plant community assembly. Acta Ecol.Sin.2019,39(7),2267-2281. (In Chinese)

30. Khatiwada JR, Zhao T, Chen YH, Wang B, Xie F, Cannatella DC, Jiang JP. Amphibian community structure along elevation gradients in eastern Nepal Himalaya. BMC Ecol.2019,19:19.

31. Wilson CD, Ek RA. Imputing plant community classifications for forest inventory plots.Ecol. Indic.2017,80,327-336.

32. Multi-scale patterns of forest structure and species composition om relation to climate in northeast China. Ecography 2012,35,1072-1082.

33. Achat DL, Deleuze C, Landmann G, Pousse N, Ranger J, Austo L. Quantifying consequences of removing harvesting residues on forest soil and tree growth-A ,meta- analysis. Forest Res. Manag. 2015,348,124-141.

\section{Additional Files}


Additional file 1: The habitat of natural Larix gmelinii forests in each plot, including latitude, longitude, elevation, slope, aspect, canopy density, climate data.

Additional file 2: The habitat of artificial Larix gmelinii forests in each plot, including latitude, longitude, elevation, slope, aspect, canopy density, climate data.

\section{Supplementary Files}

This is a list of supplementary files associated with this preprint. Click to download.

- Tables.pdf

- Calculations.png

- AdditionalFile2.csv

- AdditionalFile1.csv 